\title{
Estimated impact of black carbon deposition during pre-monsoon season from Nepal Climate Observatory - Pyramid data and snow albedo changes over Himalayan glaciers
}

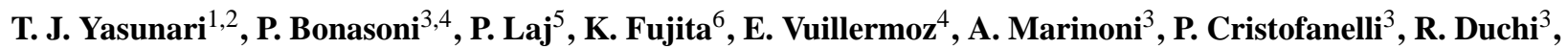 \\ G. Tartari ${ }^{7}$, and K.-M. Lau ${ }^{1}$ \\ ${ }^{1}$ NASA Goddard Space Flight Center, Greenbelt, USA \\ ${ }^{2}$ Goddard Earth Science and Technology Center, University of Maryland Baltimore County, Baltimore, USA \\ ${ }^{3} \mathrm{CNR}$ - Institute for Atmospheric Sciences and Climate, Bologna, Italy \\ ${ }^{4}$ Ev-K2-CNR Committee, Bergamo, Italy \\ ${ }^{5}$ Laboratoire de Glaciologie et Géophysique de l'Environnement, Université Grenoble 1 - CNRS (UMR5183), St. Martin \\ d'Heres, France \\ ${ }^{6}$ Graduate School of Environmental Studies, Nagoya University, Nagoya, Japan \\ ${ }^{7} \mathrm{CNR}$ - Water Research Institute, Brugherio, Italy
}

Received: 8 March 2010 - Published in Atmos. Chem. Phys. Discuss.: 14 April 2010

Revised: 3 July 2010 - Accepted: 8 July 2010 - Published: 19 July 2010

\begin{abstract}
The possible minimal range of reduction in snow surface albedo due to dry deposition of black carbon (BC) in the pre-monsoon period (March-May) was estimated as a lower bound together with the estimation of its accuracy, based on atmospheric observations at the Nepal Climate Observatory - Pyramid (NCO-P) sited at $5079 \mathrm{~m}$ a.s.l. in the Himalayan region. A total $\mathrm{BC}$ deposition rate was estimated as $2.89 \mu \mathrm{g} \mathrm{m}^{-2}$ day $^{-1}$ providing a total deposition of $266 \mu \mathrm{g}$ $\mathrm{m}^{-2}$ for March-May at the site, based on a calculation with a minimal deposition velocity of $1.0 \times 10^{-4} \mathrm{~m} \mathrm{~s}^{-1}$ with atmospheric data of equivalent $\mathrm{BC}$ concentration. Main $\mathrm{BC}$ size at NCO-P site was determined as $103.1-669.8 \mathrm{~nm}$ by correlation analyses between equivalent $\mathrm{BC}$ concentration and particulate size distributions in the atmosphere. The $\mathrm{BC}$ deposition from the size distribution data was also estimated. It was found that $8.7 \%$ of the estimated dry deposition corresponds to the estimated $\mathrm{BC}$ deposition from equivalent $\mathrm{BC}$ concentration data. If all the $\mathrm{BC}$ is deposited uniformly on the top 2-cm pure snow, the corresponding $\mathrm{BC}$ concentration is $26.0-68.2 \mu \mathrm{g} \mathrm{kg}^{-1}$, assuming snow density variations of
\end{abstract}

$195-512 \mathrm{~kg} \mathrm{~m}^{-3}$ of Yala Glacier close to NCO-P site. Such a concentration of BC in snow could result in 2.0-5.2\% albedo reductions. By assuming these albedo reductions continue throughout the year, and then applying simple numerical experiments with a glacier mass balance model, we estimated reductions would lead to runoff increases of 70-204 mm of water. This runoff is the equivalent of 11.6-33.9\% of the annual discharge of a typical Tibetan glacier. Our estimates of $\mathrm{BC}$ concentration in snow surface for pre-monsoon season is comparable to those at similar altitudes in the Himalayan region, where glaciers and perpetual snow regions begin, in the vicinity of NCO-P. Our estimates from only BC are likely to represent a lower bound for snow albedo reductions, because we used a fixed slower deposition velocity. In addition, we excluded the effects of atmospheric wind and turbulence, snow aging, dust deposition, and snow albedo feedbacks. This preliminary study represents the first investigation of $\mathrm{BC}$ deposition and related albedo on snow, using atmospheric aerosol data observed at the southern slope in the Himalayas. 


\section{Introduction}

Atmospheric aerosol has a significant direct and indirect impact on the earth's climate (IPCC, 2007). Aerosols generally scatter solar radiation. Black carbon (BC) and mineral dust, on the other hand, absorb solar radiation. Long range transport of BC and dust is well known (e.g., Hadley et al., 2007; Yasunari et al., 2009; Uno et al., 2009). Due to the large amount of absorbing aerosols present in the Atmospheric Brown Cloud (Ramanathan et al., 2007), these aerosols may be directly warming the atmosphere in the Indian-monsoon region. Lau et al. $(2006,2008)$, proposed the so-called Elevated Heat Pump (EHP) effect, whereby heating of the atmosphere by elevated absorbing aerosols strengthens local atmospheric circulation, leading to a northward shift of the monsoon rain belt, resulting in increased rainfall in northern Indian and the foothills of the Himalayas in the late boreal spring and early summer season. More recently, Lau et al. (2010) showed that the EHP effect can also lead to accelerated melting of snow cover in the Himalayas and Tibetan Plateau, by a transfer of energy from the upper troposphere to the land surface over Tibetan Plateau. In addition, BC and mineral dust depositions onto snow-surface in the cryosphere may reduce the surface albedo (e.g., Warren and Wiscombe, 1980; Aoki et al., 2006, 2007; Tanikawa et al., 2009). The impurity effect on snow albedo reduction is more important for visible wavelength than that for near infrared radiation (e.g., Warren and Wiscombe, 1980; Flanner et al., 2007). The effect increases heating of the snow and ice surface, thus accelerating melting, shortening snow duration, altering mass balance and causing the retreat of mountain glaciers. These physical activities change the amount of available water resource in the region (e.g., Hansen and Nazarenko, 2004; IPCC, 2007; Flanner et al., 2007, 2009).

The southern slope of the Himalaya is directly exposed to Indian emissions and more likely to be impacted by $\mathrm{BC}$ than the northern slope. However, the available data of $\mathrm{BC}$ deposition (BCD), for studying snow albedo reduction at the southern slopes in Himalayan regions, are still very scarce. Moreover, only a few BC concentrations (BCC) and morphological properties in the snow and ice cores, in the northern slopes of the Himalayan and Tibetan Plateau regions, have been measured thus far (Xu et al., 2006, 2009a, b; Ming et al., 2008, 2009; Cong et al., 2009, 2010). Studies on BC concentration in snowpack at the southern slope in Himalayas are less. In addition, glaciers in Himalayas are located in severe topography. Consequently, logistic constraints have severely limited data availability on snow and ice composition, as well as atmospheric composition observations. Hence, an alternative approach to estimating BCD over Himalayan glaciers is necessary for understanding the impact of $\mathrm{BCD}$ on melting glaciers.

Atmospheric data of equivalent BC concentration (eqBCC), aerosol particle number concentration and size distribution, as well as meteorological parameters, are now continuously measured at the Nepal Climate Observatory - Pyramid (NCO-P, 5079 a.s.l.) on Southern slope of the Himalayans (Bonasoni et al., 2008, 2010) (Fig. 1). The NCO-P is the highest aerosol observatory managed within the Ev-K2-CNR Stations at High Altitude for Research on the Environment (SHARE) and the United Nations Environmental Program (UNEP) Atmospheric Brown Clouds (ABC) projects. This station was established in March 2006 for atmospheric research in the Khumbu Valley, Sagarmatha National Park, near the base of the Nepalese side of Mt. Everest (5079 m a.s.1.) (http://evk2.isac.cnr.it/). Because high altitude measurement sites are relatively clean and far from anthropogenic emission sources, they offer an opportunity to study the influence of anthropogenic pollution transported from remote areas.

The Indian sub-continent, especially the Indo-Gangetic Plain is one of the largest BC emission sources in the world (Ramanathan et al., 2007) and it is in the vicinity of the Himalayan glaciers. Preliminary work of Bonasoni et al. (2008) has found very elevated eqBCC under different meteorological conditions, with well defined seasonality showing a maximum in pre-monsoon season (Marinoni et al., 2010). The aim of this study is to provide a preliminary lower bound estimate of BCD and BCC on and in the snow surface on the Himalayan region during the pre-monsoon period, based on NCO-P atmospheric observations recorded in March-May 2006. Based on the estimated BCC in snow surface, we compute the possible minimal snow albedo reduction range and the related additional snow melt runoff from a typical Tibetan glacier by simple numerical calculations with a glacier mass balance model. These calculations are the first step prior to ascertaining more precise estimates of snow albedos and snow melt runoffs from glaciers. Further detailed studies should be initiated using regional models, satellite data, and more detailed observations in Himalayan regions, including seasonal variations of atmospheric concentration and deposition of absorbing aerosols. Some parts of the Himalayan glaciers in ablation zone are covered by debris. Our discussion is not applicable to these completely debris-covered glacial surfaces. Our study will be applicable for non-debris covered (hereafter, NDC) snow surface areas in the ablation zone and other glacial zones at higher altitudes. Hopefully, this study will stimulate further research of albedo reduction and accompanied snow melt runoff from glaciers over $\mathrm{Hi}-$ malayan region.

In this study, a BCC range in the snow will be estimated by using the minimal deposition of $\mathrm{BC}$ onto the snow surface, the NCO-P data, and the typical snow density data over a Himalayan glacier (Sect. 3.2). We will also discuss the possible dilution and enrichment effect of BCC in snow by precipitation and sublimation (Sect. 3.3). The snow albedo reduction will be assessed based on an empirical relationship between snow albedo reduction rate and BCC in snow (Ming et al., 2009) in Sect. 3.4. The possible deviation range as error from our estimated snow albedo reductions will be also 
discussed in Sect. 3.5. We will calculate how much the estimated albedo reductions can possibly impact the increase of snow melt runoff from glaciers. Here we carried out some numerical experiments with a glacier mass balance model for a typical Tibetan glacier in Sect. 3.6,. In the experiment, we assumed continuous albedo reductions throughout the year. Finally, we also suggest some important points to be considered in near future studies in Sect. 3.7.

\section{Data and method to estimate $\mathrm{BC}$ deposition}

With the purpose of estimating the lower bound of snow surface albedo reductions over NDC snow surface at a typical Himalayan glacier, due to BCD, we first calculate BCC in snow surface by a fixed slower deposition velocity together with atmospheric measurements conducted at the NCO-P (Bonasoni et al., 2008, 2010): meteorological parameters (temperature, pressure, relative humidity, wind intensity, wind direction, and rain) at $30 \mathrm{~min}$. interval (VAISALA WXT510); number concentrations and size distribution of aerosol with optical diameter between 0.25 and $32 \mu \mathrm{m}$ in 31 size channels, on $30 \mathrm{~min}$. interval (OPC, optical particle counter, GRIMM\#190) and eqBCC (MAAP, Multi-Angle Absorption Photometer, 5012) in the atmosphere at $30 \mathrm{~min}$. intervals, were recorded. A recommended mass absorption coefficient of $6.6 \mathrm{~g} \mathrm{~m}^{-2}$ was used for calculating BC concentration (Petzold et al., 2002). Additional information on MAAP measurements and calibration procedures are shown by Marinoni et al. (2010). Particles with mobility diameter between 10.31 and $669.8 \mathrm{~nm}$ were determined in 117 ranges (whole size range is $3.035-995 \mathrm{~nm}$, but data in 10.31$669.8 \mathrm{~nm}$ were only available and used) by Scanning Mobility Particle Sizer (SMPS) on $1 \mathrm{~h}$ interval. The inlet of all these measurements was placed at $3.5 \mathrm{~m}$ above ground level (a.g.l.). As a first step, we determined the main BC particle size and estimated the amount of BCD on the snow surface during pre-monsoon season 2006 from the eqBCC, OPC number concentration, and SMPS size distribution data observed at the NCO-P. With the aim of determining the main particle size range of atmospheric eqBC, we carried out correlation analyses between the number counts in each diameter bin of OPC and SMPS and eqBCC in the air. In cases where data were unavailable at a specific time, the whole set of necessary data on calculation was deleted. We used the middle time of the averaged observation slot time for plotting data.

Next, with the aim of calculating minimal BCD flux at the surface, we consider a deposition velocity. The estimated BCD flux will be used to estimate BCC in snow surface and its impact on snow surface albedo reductions. As to deposition velocity, here, we consider a constant minimal deposition velocity of $1.0 \times 10^{-4} \mathrm{~m} \mathrm{~s}^{-1}$. In general, detailed deposition velocity is considered as:

$v_{d}=1 /\left(r_{a}+r_{b}+r_{c}\right)+v_{s}$,

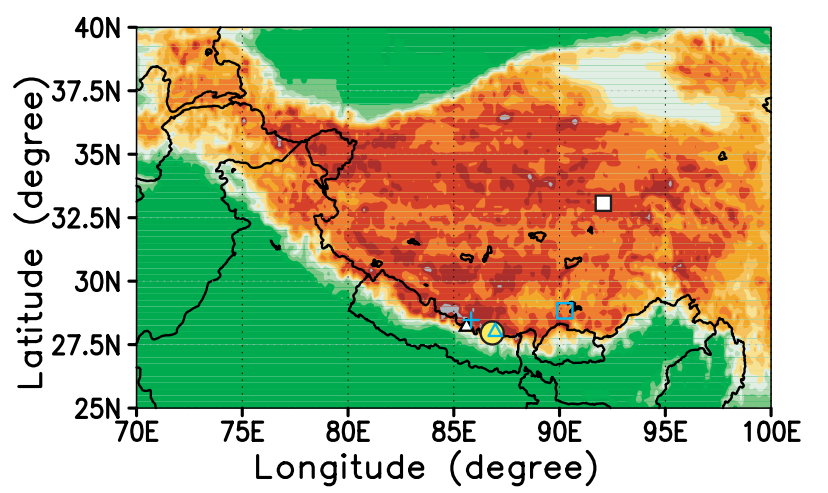

10001500200025003000350040004500500055006000 (m)

Fig. 1. Location map of research sites focused in this study. The large circle in yellow denotes NCO-P site. The triangle and square in white colour denote the locations of Yala Glacier, and Dongkemadi Glacier, respectively. The cross, triangle, and square in sky blue denote the locations of Kangwure Glacier, East Rongbuk Glacier, and Qiangyong Glacier, respectively, where BC concentrations in snow were measured by Xu et al. (2006) and Ming et al. (2008, 2009). The Merged IBCAO/ETOPO5 Global Topographic Data Product by Holland (2000) was used for topography map.

where $r_{a}, r_{b}, r_{c}$, and $v_{s}$ are aerodynamic resistance above canopy, quasi-laminar layer resistance, surface resistance, and terminal velocity by gravitational settling, respectively (Han et al., 2004). Deposition velocity is higher over land than over sea. The deposition velocities in different particle size over land are mostly faster than $1.0 \times 10^{-4} \mathrm{~m} \mathrm{~s}^{-1}$ (NhoKim et al., 2004). Hence, our deposition velocity used in this study will be expected as a slower value than deposition velocities in general diurnal cycles over land and considered as lower bound deposition velocity, minimal value, of deposition velocity.

Using the minimal deposition velocity, the 1-hourly total amount of $\mathrm{BC}$ deposition rate will be then accumulated over the three-month period to obtain the total mass of $\mathrm{BC}$ deposited on snow surface.

\section{Results and discussions}

\subsection{Determination of $\mathrm{BC}$ size range and deposition rate}

While the MAAP instrument specifically measures the aerosol absorption coefficient, directly related to BCC, both the OPC and SMPS measures total aerosol number concentration and size distributions of all aerosol components including $\mathrm{BC}$. To ascertain the typical size range of $\mathrm{BC}$, the correlation analyses between counts in OPC and SMPS bins and eqBCC in the atmosphere were carried out in time series data (Fig. 2a and b). Higher correlation coefficients (more than 0.8 ) were seen in the ranges $280-650 \mathrm{~nm}$ for OPC- 


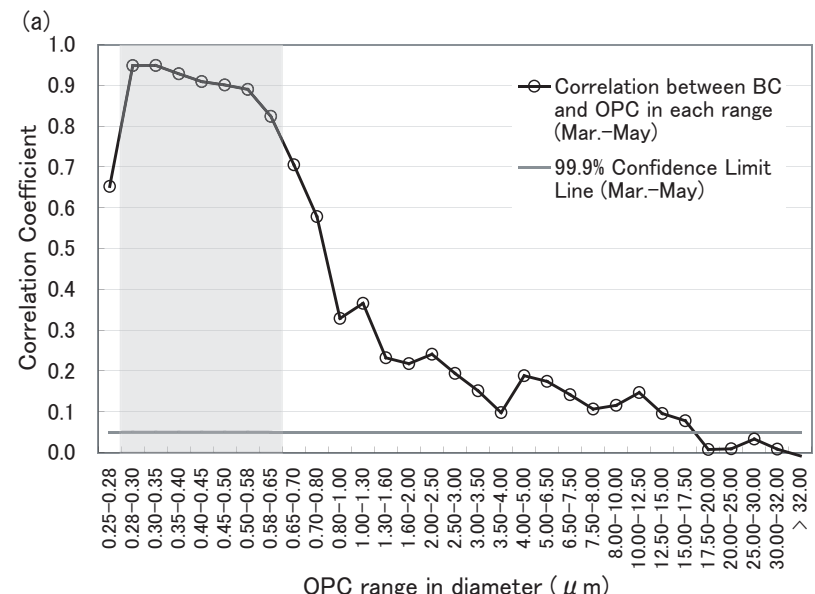

(b)

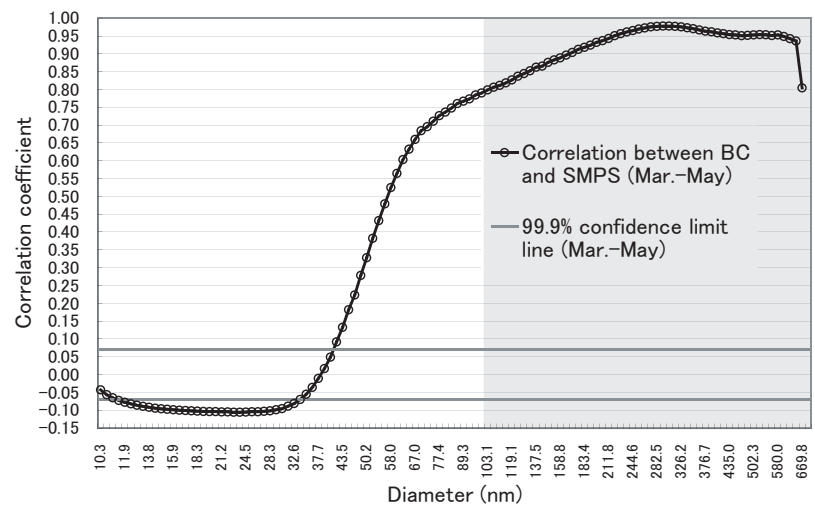

Fig. 2. Correlation coefficients (black solid line with circle) for March-May in time series data between atmospheric eqBCC and (a) particle counts in each size (as measured by OPC); (b) (as measured by SMPS). The bold line in gray denotes $99.9 \%$ confidence limit lines. The shade size ranges correspond to the correlation coefficient of more than 0.8 .

eqBCC and 103.1-669.8 nm for SMPS-eqBCC, respectively. This confirms that the $\mathrm{BC}$ particles at NCO-P preferably have sizes ranging between 100 and $670 \mathrm{~nm}$, as indicated by the high correlation between eqBCC and PM-1 showed by Marinoni et al. (2010). The MAAP measures BCC as eqBCC in the atmosphere, since Marinoni et al. (2010) found the negligible dust contribution to aerosol absorption coefficient at NCO-P. In order to reduce any miscounting due to absorbing organic carbon, we chose significantly higher correlations $(r>0.8)$ as BC particle existence. In fact, previous study (Venzac et al., 2008) found much smaller particles (10 $20 \mathrm{~nm}$ growing up to $40 \mathrm{~nm}$ ) possibly related to the mode of new particle formation from gaseous or ionic precursors at this site, while larger fraction $(>600 \mathrm{~nm})$ of submicron particles is generally present at low concentrations.

Less precipitation has been observed in Khumbu valley during pre-monsoon season (Bollasina et al., 2002; Bonasoni et al., 2008, 2010). As deduced by NCO-P data (Bonasoni et al., 2008, 2010), in the high Khumbu valley during
March-May 2006, precipitation events were only 1.9\% of all the available meteorological data during March-May 2006 and the total precipitation amount was very low $(6.9 \mathrm{~mm})$. Hence, it is reasonable to assume that the main cause for $\mathrm{BC}$ removal in the atmosphere in this season was due to dry deposition.

The minimal BC dry deposition flux at the surface was estimated from MAAP and SMPS data, separately. Because enough observation instruments are not always available for field observations, we should consider some ways to estimate BCD from limited observations. At the NCO-P site, eqBCC and SMPS are now available. Using both, we considered two types of BCD estimations. First, the total BC mass deposition flux per $1 \mathrm{~h}$ was calculated using eqBCC data from MAAP as $($ eqBCC) $\times$ (the minimal deposition velocity of $\left.1.0 \times 10^{-4} \mathrm{~m} \mathrm{~s}^{-1}\right) \times($ interval time $=3600 \mathrm{~s})$. We summated the BC flux for March-May and obtained total deposition amount of BC of $266 \mu \mathrm{g} \mathrm{m}^{-2}\left(=2.89 \mu \mathrm{g} \mathrm{m}^{-2} \mathrm{day}^{-1}\right)$. Second, we also estimated total dry deposition flux per $1 \mathrm{~h}$ from SMPS data as $\sum$ (BC mass concentration in each size bin) $\times$ (the minimal deposition velocity of $1.0 \times 10^{-4} \mathrm{~m} \mathrm{~s}^{-1}$ for each size bin) $\times$ (interval time $=3600 \mathrm{~s})$. In the calculation, we assumed 1) uniform BCC in the atmospheric layer from the ground to the measurement height of $3.5 \mathrm{~m}$ a.g.l. and 2) $\mathrm{BC}$ continuously depositing onto the surface. The mass concentrations in the atmosphere in each size bin were calculated from SMPS data, considering spherical particles with a reference particle density (here we used a BC density of $2000 \mathrm{~kg} \mathrm{~m}^{-3}$ by Lindstedt, 1994). It is because the SMPS covers a wider range of particle size than that of OPC for the small particles, and the correlations between eqBCC, and OPC - SMPS counts give similar results as shown in Fig. 2a and $b$, except for the smaller diameters that are not available in OPC. The interval of SMPS data was $1 \mathrm{~h}$ and continuous depositions during this interval were assumed. The values of $d \log D$ in each bin were used for converting size distribution data $(d N / d \log D)$ to number concentration data. Then total dry deposition amount of $3059 \mu \mathrm{g} \mathrm{m}^{-2}$ was obtained for the period of March-May. The SMPS data include more aerosol information than MAAP and this deposition amount may include not only BC but also other aerosol particles. If we compare the total dry deposition amount from SMPS with the total BC deposition amount of $266 \mu \mathrm{g} \mathrm{m}^{-2}$ from MAAP, the estimated BC deposition amount from MAAP is $8.7 \%$ of the total dry deposition amount from SMPS. This is somewhat consistent with the observed mass contribution of Elemental Carbon in aerosol at NCO-P (Decesari et al., 2010) and soot abundance at Mt. Qomolangma (Everest) (Cong et al., 2010). Hence, we considered that approximately $8.7 \%$ of total dry deposition amount from SMPS data is likely composed of BC at NCO-P site. Then, 1-hourly dry deposition amount from SMPS data was converted to 1-hourly BCD amount multiplied by a coefficient of 0.087 . The estimated BCD from MAAP was mainly used for the discussions on $\mathrm{BC}$ concentrations in snow and related albedo reductions. 
Although MAAP and SMPS were different observations, the variations of the estimated BCD from SMPS data were superimposed on the atmospheric eqBCC from MAAP (Fig. 3a; red). It indicates that the 1-hourly BCD amount estimated from SMPS data with the coefficient of 0.087 for the particle size range of $103.1-669.8 \mathrm{~nm}$ was well explained by eqBCC variations in the atmosphere. The large variability in Fig. 3a is mostly driven by diurnal cycles of BCD. The diurnal cycle shows clearly a midnight-morning low and an afternoon high BCD rates, consistent with the diurnal cycle of dry convection in this region during the pre-monsoon periods (Fig. 3b). The same diurnal cycle was seen for aerosol scattering and absorption coefficients at NCO-P site (Marcq et al., 2010). A few acute episodes of BC pollution have been observed in this period (eqBCC exceeded some thousand of $\mathrm{ng} \mathrm{m}^{-3}$ ), leading to an estimated dry deposition of BC larger than $1 \mu \mathrm{g} \mathrm{m}^{-2} \mathrm{~h}^{-1}$. Although we used a fixed deposition velocity as a considered minimal value for the estimated BCD amount, expected faster deposition velocity will likely increase our estimated $\mathrm{BCD}$ rate.

\subsection{Estimation of $\mathrm{BC}$ concentration in surface snow}

The total mass of BC deposited on the surface during 2006 pre-monsoon season was estimated as the sum of the BCD integrated the 3-month period with available data. Based on this, we obtained a total BCD amount of $266 \mu \mathrm{g} \mathrm{m}^{-2}$ for the pre-monsoon season, corresponding to $2.89 \mathrm{\mu g} \mathrm{m}^{-2}$ day $^{-1}$. As indicated in Sect. 3.1, most likely, this value represents the lowest line of the actual BCD. Most of the glaciers in Nepal generally exist above the altitude of the NCO-P while their ablation basin levels are close to its altitude (Karma et al., 2003). Most of the glacier melting occurs in ablation areas. The equilibrium line altitudes of these glaciers are also above the NCO-P level. Hence, our discussion from the estimated BCD can be applicable to the ablation zone of NDC parts of those glaciers.

The 2-cm top layer (5-cm top layer in Aoki et al., 2000) of snow surface is more contaminated than the deeper part of the snow layer because the snow impurities are derived from dry depositions of atmospheric aerosols (Aoki et al., 2000, 2007; Tanikawa et al., 2009). Moreover, the surface layer contributes to a large fraction of the semi-infinite albedo in snow contaminated by soot and mineral dust (Tanikawa et al., 2009). In addition, Tanikawa et al. (2009) showed that the mass concentrations of snow impurities deposited in the surface layer of $\sim 2 \mathrm{~cm}$ were about $30-50 \mathrm{ppmw}$ whereas that the concentrations in $2-10 \mathrm{~cm}$ were about $2-6 \mathrm{ppmw}$. This difference in characteristics between surface layer and lower snow layer were consistent for elemental carbon, organic carbon, and dust in their study. It indicates that the impurity concentration at the top 2-cm is much higher than that below $2 \mathrm{~cm}$ and the top snow layer is considered the key to assessment of albedo reductions. Hence, our focus on $2-\mathrm{cm}$ snow
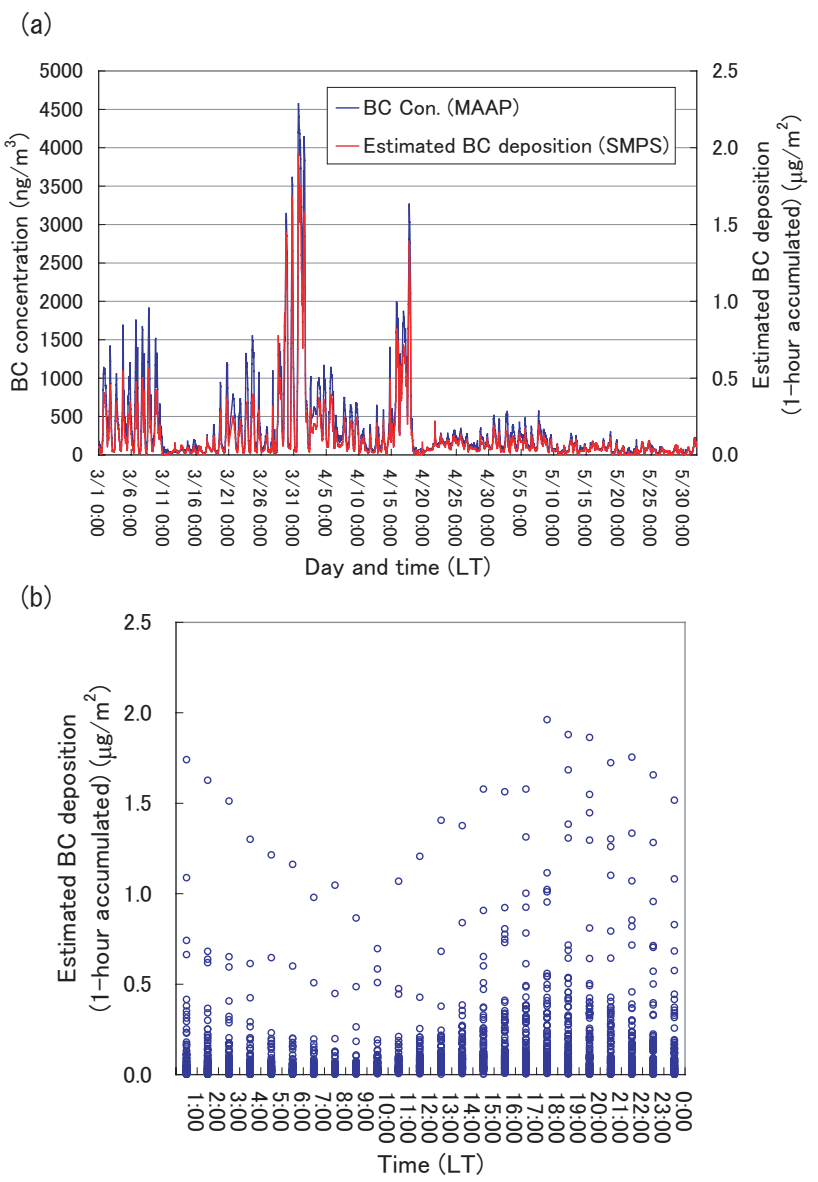

Fig. 3. (a) One-hour mean eqBCC from MAAP data (Bonasoni et al., 2008) and estimated hourly total BCD flux (right side scale) as multiplying dry deposition amount from SMPS data by 0.087 during March-May in 2006; (b) Composite of the estimated hourly total BCD flux during March-May in 2006.

surface is reasonable for albedo reduction calculations as a preliminary estimate.

To calculate the BCC in the top layer of snow, we assumed that the total $\mathrm{BC}$ is uniformly distributed in the top $2 \mathrm{~cm}$ pure snow. Because BCC depends on snow water content, and no data on snow density are available for NCO-P area, we used observed surface snow density data at the nearby Yala Glacier by Fujita et al. (1998) (Table 1). The glacier is located in the Nepalese Langtang Valley $\left(28.23^{\circ} \mathrm{N} ; 85.60^{\circ} \mathrm{E}\right.$; $2.5 \mathrm{~km}^{2}$, between $5094-5749 \mathrm{~m}$ of altitude) about $123 \mathrm{~km}$ away the NCO-P and at very similar altitude (Fig. 1). An assumption of pure snow layer of deeper than $2 \mathrm{~cm}$ can significantly increase the pure water amount, thus reducing BCC within the same amount of BCD. However, an assumption of a deeper pure snow layer is not realistic, based on the studies as mentioned above (Aoki et al., 2000, 2007; Tanikawa et al., 2009). Moreover, snow layers below $2 \mathrm{~cm}$ usually include impurities to some extent in the real world. 
Table 1. Surface snow density at Yala glacier (5450 m).

\begin{tabular}{lcc}
\hline Date & Depth $(\mathrm{cm})$ & $\rho\left(\mathrm{kg} \mathrm{m}^{-3}\right)$ \\
\hline $1996 / 5 / 20$ & 3 & 320 \\
$1996 / 6 / 23$ & 5 & 512 \\
$1996 / 6 / 27$ & 3 & 338 \\
$1996 / 7 / 28$ & 3 & 468 \\
$1996 / 8 / 3$ & 7 & 426 \\
$1996 / 8 / 3$ & 2 & 413 \\
$1996 / 8 / 23$ & 5 & 389 \\
$1996 / 8 / 31$ & 2.5 & 357 \\
$1996 / 10 / 9$ & 5 & 195 \\
\hline
\end{tabular}

As the NCO-P altitude corresponds to the lowest elevation of Yala glacier, our estimated BCD can be considered to be applicable to the termini of NDC parts of glaciers at similar elevations in Nepal as reported in Karma et al. (2003). Therefore, we also assume that transport along valleys and $\mathrm{BC}$ source strength can be similar to those at the high Kumbu valley. If the total $\mathrm{BC}$ of $266 \mu \mathrm{g} \mathrm{m}^{-2}$ is deposited on $2-\mathrm{cm}$ thickness of pure snow, without pre-existing or other contamination such as dust, then BCC in the snow surface will vary within the range of $26.0-68.2 \mu \mathrm{g} \mathrm{kg}^{-1}$ due to snow density variations between $195-512 \mathrm{~kg} \mathrm{~m}^{-3}$ in Table 1 . These estimated concentrations are in agreement with BCC at other glaciers in the Himalayan region (Table 2). From Table 2, we also note that the upper limit of the NCO-P estimated BC snow concentration exceeds the values observed at other locations on the northern slope of the Himalayan range. In particular the East Rongbuk glacier, approximately $16 \mathrm{~km}$ from the NCO-P but on the opposite side of Mt. Everest, shows the lowest BCC (Table 2). Ming et al. (2008) also found in the same East Rongbuk glacier area the highest level of BCC, $20.3 \pm 9.2 \mu \mathrm{g} \mathrm{kg}^{-1}$, during the period 1995-2002, exceeding $50 \mu \mathrm{g} \mathrm{kg}-1$ in the summer of 2001 showing a significant trend in increased concentration of BCC. Our results, together with the cited studies, suggest that, on the southern slope of the Himalayas, the influence of polluted air masses, that are transported from the Indo-Gangetic Plain, and driven by valley breezes up to high mountain and glaciers, have a significant impact (Bonasoni et al., 2008).

\subsection{Estimation of dilution effect at the snow surface on BC concentration}

Precipitation onto snow surface dilutes BCC in snow; nevertheless pre-monsoon season is well known as dry season in South Asian region and a low precipitation amount $(6.9 \mathrm{~mm})$ was observed at NCO-P during March-May 2006. Due to the dryness of the period, we expect that most of the aerosol fallout was due to dry deposition as mentioned in Sect. 3.1. To support the discussion on BCC in snow without much dilution effect by precipitation during pre-monsoon season, we also examined the dilution effect on BCC in the snow surface. Assuming that there are few differences in precipitation amounts between NCO-P site and Yala Glacier, because of similar altitude and vicinity, we considered precipitation at NCO-P to be the same as that at Yala Glacier. Then, we used the same precipitation amount over Yala Glacier. The air temperature over Yala Glacier was also estimated from NCO-P air temperature data (Fig. 4) with temperature lapse rate of $6.5 \mathrm{~K} \mathrm{~km}^{-}{ }^{1}$. The air temperature at the altitude over Yala Glacier fell below freezing during most of the time in March-May (Fig. 4). Thus, most of the precipitations were expected as snowfall. When it snows, snow depth slightly increased with a typical fresh snow density of $110 \mathrm{~kg} \mathrm{~m}^{-3}$. As deduced by NCO-P observation, the largest amount of precipitation occurred during 18:30-19:00 (30 min) on 18 May (Fig. 4). However, this could contribute to an increase of only $2 \mathrm{~cm}$ of snow depth by fresh snow (hereafter called, Event A). Total precipitation amount during March-May was only $6.9 \mathrm{~mm}$ w.e., indicating that the pre-monsoon was very dry in 2006 and most of the aerosol fallout was considered to be dry deposition as mentioned in Sect. 3.1. It is noted that the above example cannot be generalized for all the years, because there could be large interannual variability in premonsoon snowfall over this region.

For the sake of discussing dilution effect on BCC in snow by precipitation, we also calculated the evaporation amount $(E)$ from the snow surface (sublimation if the snow surface temperature was below 0 degree in Celsius) every $30 \mathrm{~min}$. by using a bulk equation. In the calculation, estimated air and snow surface temperatures over Yala Glacier at altitude of $5450 \mathrm{~m}$ were used. For estimating snow surface temperature quantitatively, we need irradiance data. However, NCO$\mathrm{P}$ site did not measure irradiance data during March-May 2006. Hence, we assumed snow surface temperature as -9 , -4 , and $-1{ }^{\circ} \mathrm{C}$ during 1 March-29 April, 30 April-23 May, and 24 May-31 May, respectively (Fig. 5), compared to the estimated air temperature over Yala Glacier in Figs. 4 and 5. In general, snow temperature fluctuations are much lower than that of air temperature. Based on the characteristics, our values of snow surface temperature are considered to be realistic.

Then, we calculated the evaporation (sublimation in this study) amount ( $E$ ) by a bulk equation as follows:

$E=\rho_{\mathrm{AIR}} C_{H} U\left(Q_{\mathrm{SAT}}(T s)-\mathrm{RH} \times Q_{\mathrm{SAT}}\left(T_{A}\right)\right) \times \mathrm{DT}$,

where $\rho_{\mathrm{AIR}}, C_{H}, U, Q_{\mathrm{SAT}}\left(T_{S}\right), Q_{\mathrm{SAT}}\left(T_{A}\right), \mathrm{RH}$ and $\mathrm{DT}$ are air density, a bulk coefficient $(=0.002)$, wind speed, saturated specific humidity at the snow surface, saturated specific humidity in the atmosphere, relative humidity in percentage divided by 100 , and total time in second for $30 \mathrm{~min}$. (=1800 s). The fixed air pressure at the altitude of Yala Glacier was also used for this calculation. The direction from the snow surface to the atmosphere is defined as positive in the equation. 
Table 2. Comparison between estimated (a) and observed (b, c, d, e, f) BCCs in surface snow and ice core for locations reported in Fig. 1.

\begin{tabular}{lcc}
\hline $\begin{array}{l}\text { Site in Himalayan } \\
\text { region }\end{array}$ & $\begin{array}{c}\text { Altitude } \\
(\mathrm{m})\end{array}$ & $\begin{array}{c}\text { BCCsin snow and } \\
\text { ice core }\left(\mu \mathrm{g} \mathrm{kg}^{-1}\right)\end{array}$ \\
\hline${ }^{\mathrm{a}}$ NCO-P (lat. 27.958, lon. 86.815) & 5079 & $26.0-68.2^{\mathrm{e}}$ \\
${ }^{\mathrm{b}}$ Qiangyong Glacier (lat. 28.83, lon. 90.25) & 5400 & 43.1 \\
${ }^{\mathrm{b}}$ Kangwure Glacier (lat. 28.47, lon. 85.82) & 6000 & 21.8 \\
${ }^{\mathrm{c}}$ East Rongbuk Glacier (lat. 28.02, lon. 86.96) & 6465 & 18.0 \\
${ }^{\mathrm{d}}$ East Rongbuk Glacier (lat. 28.02, lon. 86.96) & 6500 & $20.3 \pm 9.2$ \\
\hline
\end{tabular}

a This work.

$\mathrm{b}$ The EC concentration data in snow sample by Xu et al. (2006).

c The BCC data in snow sample by Ming et al. (2009).

$\mathrm{d}$ The BCC data during 1995-2002 in an ice core by Ming et al. (2008). The BCC exceeded 50 $\mathrm{\mu g} \mathrm{kg}^{-1}$ in the summer of 2001.

${ }^{\mathrm{e}}$ Estimated BCC in 2-cm surface snow with density variations of $195-512 \mathrm{~kg} \mathrm{~m}^{-3}$ at Yala Glacier (see, Fig. 1).

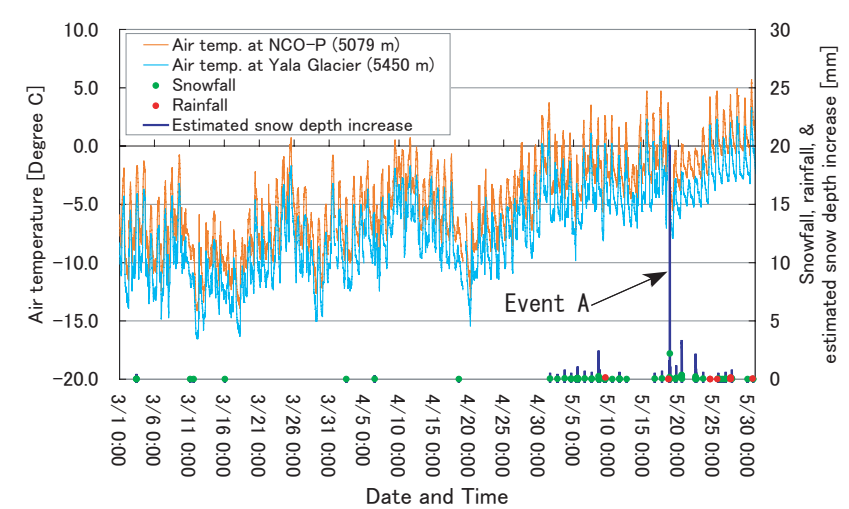

Fig. 4. Air temperature variations at NCO-P site and over Yala Glacier, together with the amount of snowfall and rainfall, and estimated snow depth increases over Yala Glacier. The air temperature over Yala Glacier was estimated with a temperature lapse rate of $6.5 \mathrm{~K} \mathrm{~km}^{-1}$. If air temperature was below 0 degree in Celsius, precipitation was considered to be snow. The snow depth increases were calculated with a typical fresh snow density of $110 \mathrm{~kg} \mathrm{~m}^{-3}$.

The difference between precipitation $(P)$ and evaporation $(E)$ (or sublimation) $(P-E)$ shows the amount of water vapor transport between the snow surface and the atmosphere. In Fig. 5, the values of $P-E$ showed negative values over most of the pre-monsoon periods indicating dominant water vapor transport from the snow surface to the atmosphere. Hence, sublimation was likely prominent and dry condition continued during March-May 2006. Before Event A shown in Figs. 4 and 5b, total amount of $P-E$ was $-23.6 \mathrm{~mm}$ w.e. and that after and including Event A, the amount was $3.6 \mathrm{~mm}$ w.e. Total amount of $P-E$ during March-May is $-20.0 \mathrm{~mm}$ w.e. Bonasoni et al. (2010) mentioned that VAISALA can underestimate total precipitation due to the omission of snowfalls. However, even if we expect the total precipitation amount of $6.9 \mathrm{~mm}$ was $50 \%$ of the true value of total precipitation amount, still the water vapor

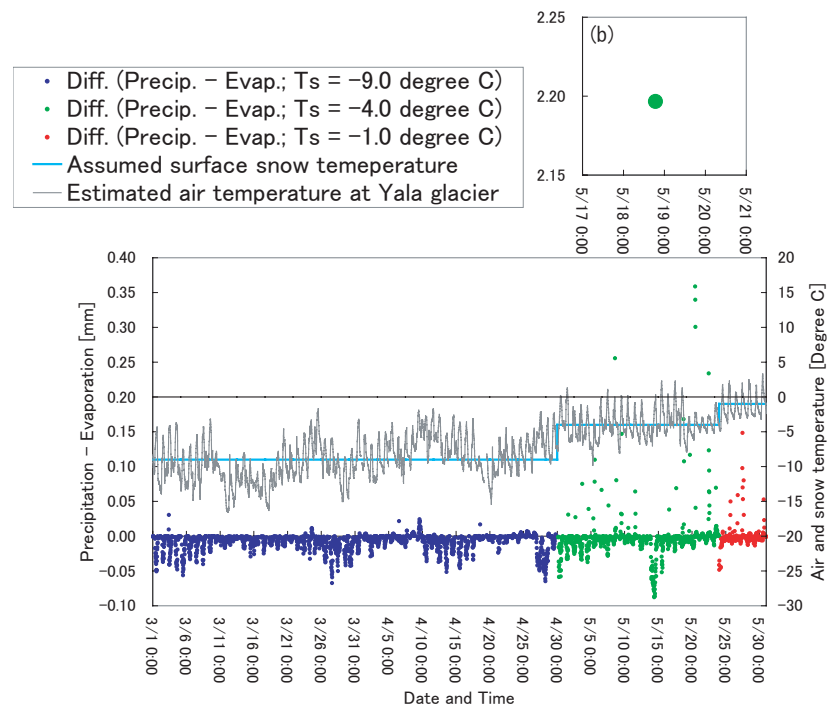

Fig. 5. Difference between precipitation $(P)$ and estimated evaporation $(E)$ (sublimation in this study). The constant snow surface temperatures of $-9,-4$, and $-1{ }^{\circ}$ were used during 1 March-29 April, 30 April-23 May, and 24 May-31 May, respectively. One data in $P-E$ at the time of Event A was located out of range and plotted in Fig. 5b separately. In Fig. 5b, vertical and horizontal axes have the same units as Fig. 5 a.

loss from snow surface was more dominant than precipitation. It implies that higher probability of enrichment of BC at the snow surface due to water loss from the snow surface is expected during March-May rather than the dilution effect by precipitation. Our estimates of BCC in 2-cm snow surface of $26.0-68.2 \mu \mathrm{g} \mathrm{kg}^{-1}$ did not include the effect of this enrichment of $\mathrm{BC}$ due to the water loss from the snow surface. If we consider this effect, $\mathrm{BCC}$ in the snow surface during premonsoon period could be even higher. In conclusion, our estimates of BCC are considered to be "lower bound" values without including the enrichment effect of $P-E$. 


\subsection{Estimation of snow albedo reduction}

To estimate the changes in snow surface albedos from the estimated total BCD of $266 \mu \mathrm{g} \mathrm{m} \mathrm{m}^{-2}$ during March-May 2006, we used the linear regression equation $\left(R^{2}=0.9951\right)$ by Ming et al. (2009):

Snow_albedo_reduction $=0.0757 \times \mathrm{BCC}+0.0575$.

This was obtained from the relationship between BCC in snow and potential albedo reductions, derived from a variety of snowpack observations and model calculations. For the given range of snow density and BCC in snow, we found the range of albedo reduction to be from 2.0 to $5.2 \%$ during pre-monsoon period (Fig. 6). This range is significantly higher than the albedo reduction (1\%) found by Grenfell et al. (1994) for a uniform distribution of $15 \mu \mathrm{g} \mathrm{kg}^{-1} \mathrm{BC}$ in snow, as indicated by the calculation of Warren and Wiscombe (1980). Flanner et al. (2007) indicated that the addition of $500 \mathrm{\mu g} \mathrm{kg}^{-1}$ of $\mathrm{BC}$ to snow decreased its visible albedo approximately $10 \%$ in visible wavelengths, and calculated that the instantaneous forcing over the Tibetan Plateau, due to the presence of $\mathrm{BC}$ in snow, exceeds $20 \mathrm{~W} \mathrm{~m}^{-2}$ in some places. Because snow aging process may also accelerate more $\mathrm{BC}$ accumulations onto snow surface (Xu et al., 2006), and because our BCD was determined considering only dry deposition, our numbers are likely to underestimate the actual albedo reduction for NDC parts of Himalayan glaciers.

\subsection{Estimation of the albedo in function of different type of snow age and $\mathrm{BC}$}

In reality, the albedo decrease caused by $\mathrm{BC}$ depends on a wider range of environmental factors such as snow grain size, solar zenith angle, and snow depth (e.g., Warren and Wiscombe, 1980). However, the application of the regression Eq. (3) is probably adequate for a first estimate of albedo changes, because our aim in this study is to determine the minimal level of possible albedo reductions due to BCD. Ice layer is sometimes seen at NDC glacial surface, but the results obtained by using the Eq. (3) can be applied to the NDC snow surface composed of fresh, compacted, and granular snow grains (not complete ice) because most of the original data for snow albedo estimations were based on some assumptions of snow grain size, in which the snow density range is similar to that of Yala glacier in Table 1.

The albedo reductions obtained from the regression equation by Ming et al. (2009) may provide lower bound of albedo reductions as mentioned in Sect. 3.4. However, the estimate of albedo reduction, in general, includes some errors and we need to estimate the possible deviation range in the estimation by using regression Eq. (3). The data used in this study were obtained from the Supporting Table 4 in Hansen and Nazarenko (2004) (see the website at: http://www.pnas.org/content/suppl/2003/12/15/

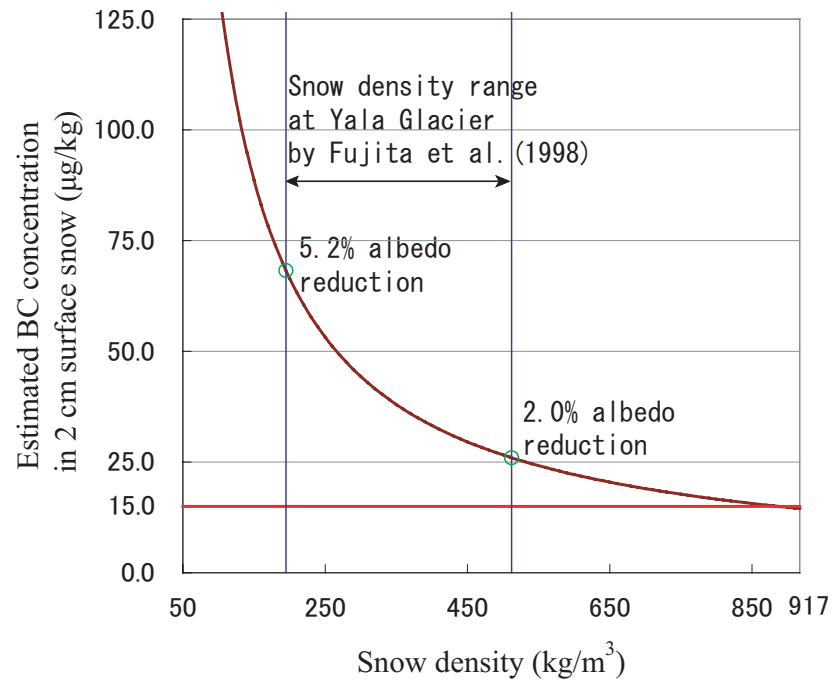

Fig. 6. The relationship between snow density and the calculated BCC in surface snow together with related albedo reductions. The brown curved and red lines denote the estimated BCD of $266 \mu \mathrm{g}$ $\mathrm{m}^{-2}$ from NCO-P data and the $1 \%$ albedo reduction line by BCC of $15 \mu \mathrm{g} \mathrm{kg}^{-1}$ in snow mentioned in Grenfell et al. (1994) indicated by the calculations of Warren and Wiscombe (1980). The range between two blue solid lines corresponds to the range of snow density variations of $195-512 \mathrm{~kg} \mathrm{~m}^{-3}$ in surface snow at Yala glacier by Fujita et al. (1998). The green circles are estimated maximal and minimal albedo reductions due to $\mathrm{BCC}$ in snow by using a linear regression equation of Ming et al. (2009).

2237157100.DC1/7157Table4.html), 2.3\% albedo reduction by BCC of $25 \mu \mathrm{g} \mathrm{kg}^{-1}$ by Jacobson (2004), $1 \%$ albedo reduction by BCC of $15 \mu \mathrm{g} \mathrm{kg}^{-1}$ by Grenfell et al. (1994) with the model of Warren and Wiscombe (1980). The estimates of albedo reductions from observed $\mathrm{BC}$ concentrations in snow by Hansen and Nazarenko (2004) were based on Fig. 2 of Warren and Wiscombe (1985). Hence, the estimated albedo reductions are based on the calculation of the albedo model of Warren and Wiscombe (1985). They calculated the albedo reductions as external mixture case of $\mathrm{BC}$ for new and old snows and also mentioned the importance of internal mixture to explain true effect of soot. Therefore, in the study of Hansen and Nazarenko (2004), the estimate for internal mixing increased the $\mathrm{BC}$ absorption coefficient, or effective amount, by a factor of two along the descriptions by Warren and Wiscombe (1985). In the calculation of Warren and Wiscombe (1985), new and old snows are considered as the grain radius sizes of $0.1 \mathrm{~mm}$ and $1.0 \mathrm{~mm}$, respectively. The meteorological condition was expected as subarctic summer, clear sky, and solar zenith angle effect of $53^{\circ}$ at sea level in their estimates. The albedo reduction rates were estimated at the wavelength of $470 \mathrm{~nm}$ in their calculation, at which snow albedo is most sensitive to soot content. Finally, Hansen and Nazarenko (2004) categorized BC and snow into 2 types of BC with 2 types of snow condition (4 types) (Table 3 ). 
Table 3. Regression equations of each mixture state of BC and snow type.

\begin{tabular}{lllrrr}
\hline Mixture State & Snow type & Regression equation & $R^{2}$ & $N$ & $\sigma y[\%]$ \\
\hline \multirow{2}{*}{ Ext } & New & Eq. (1) $y=-8.08653 \mathrm{E}-05 \mathrm{x}^{2}+4.79226 \mathrm{E}-02 \mathrm{x}+2.97897 \mathrm{E}-01$ & 0.99 & 14 & 0.18 \\
& Old & Eq. (2) $y=1.51204 \mathrm{E}-01 \mathrm{x}+6.85961 \mathrm{E}-01$ & 0.98 & 10 & 0.49 \\
Int & New & Eq. (3) $y=-1.20051 \mathrm{E}-04 \mathrm{x}^{2}+6.94225 \mathrm{E}-02 \mathrm{x}+6.59244 \mathrm{E}-01$ & 0.98 & 14 & 0.45 \\
& Old & Eq. (4) $y=2.20386 \mathrm{E}-01 \mathrm{x}+1.51181$ & 0.96 & 10 & 1.06 \\
\hline
\end{tabular}

Note: external mixture of BC with new snow (Ext/New), external mixture of BC with old snow (Ext/Old), internal mixture of BC with new snow (Int/New), and internal mixture of BC with old snow (Int/Old) were categorized by Hansen and Nazarenko (2004).

Therefore, we used 2 types of BC with 2 types of snow condition and calculated each regression equation from the employed data with the estimated error (Fig. 7 and Table 3). The data from Jacobson (2004) and Grenfell et al. (1994) with the model of Warren and Wiscombe (1980) were put into the categories of Int/New and Ext/New, respectively. The errors between the employed and estimated albedo reduction data from the regression equations are within $1 \%$ (Table 3 ). There are large differences among the estimated albedo reductions by each type with each equation (Fig. 7a and b). Warren and Wiscombe (1985) explained that a given amount of soot causes a greater reduction in albedo in old snow than in new snow because the radiation penetrates deeper on average in old coarse grained snow and therefore encounters more absorbing material before being scattered back out of the snowpack.

Most of the estimated values on albedo reduction, using the equation of Ming et al. (2009) for BCC of 26.0 $68.2 \mu \mathrm{g} \mathrm{kg}^{-1}$, were found within the range of those in Ext/New and Int/New (Fig. 7b). The snow albedo reduction for BCC of $68.2 \mu \mathrm{g} \mathrm{kg}^{-1}$, using the method of Ming et al. (2009), slightly exceeded the value by Int/New (Fig. 7b). Most of the estimated albedo reductions were located in the middle values of albedo reductions in new snow condition. Hence, the range of albedo reductions between Ext/New and Int/New in Fig. $7 \mathrm{~b}$ may correspond to the approximate errors in our estimation of albedo reductions. As mentioned in Fig. 4, there were fewer precipitation events during premonsoon season in 2006. Also, the snow surface is considered old aged snow over the NDC parts of Himalayan glaciers during most of March-May. It also indicates that the snow surface albedo would probably reduce along the Ext/Old or Int/Old regression lines shown in Fig. 7. If we use the equations of Ext/Old and Int/Old, much more albedo reductions are expected even if we only take BC into account. In those cases with Eqs. (2) and (4) in Table 3, the snow albedo for Ext/Old and Int/Old can possibly decrease by $4.6-11.0 \%$ and $7.2-16.5 \%$, respectively (Table 4 ). These albedo reductions are significantly higher than those found using the equation by Ming et al. (2009) $(2.0-5.2 \%$ albedo reductions). These results show that our estimate of albedo reduction is lower line.
Table 4. Possible albedo reductions by different equations on the relationship between $\mathrm{BC}$ concentration and reduced albedo.

\begin{tabular}{lcc}
\hline Equations & $\begin{array}{c}\text { Surface snow } \\
\text { density }\left[\mathrm{kg} \mathrm{m}^{-3}\right]\end{array}$ & $\begin{array}{c}\text { Reduced } \\
\text { albedo [\%] }\end{array}$ \\
\hline Eq. by Ming et al. (2009) & 195 & 5.2 \\
Eq. (1) & 512 & 2.0 \\
& 195 & 3.2 \\
Eq. $(2)^{\mathrm{a}}$ & 512 & 1.5 \\
& 195 & 11.0 \\
Eq. (3) & 512 & 4.6 \\
Eq. $(4)^{\mathrm{a}}$ & 195 & 4.8 \\
& 512 & 2.4 \\
& 195 & 16.5 \\
\hline
\end{tabular}

${ }^{\text {a }}$ Equations from Table 3 were used for estimating possible albedo reductions.

\subsection{Numerical experiment on albedo changes and increasing snow melt runoff}

Last, we carried out numerical experiments to evaluate the influence of the albedo changes on glacier melting run-off from the Tibetan glacier with the glacier mass-balance-model by Fujita (2007) and Fujita et al. (2007). The model calculates the melt water, refrozen water, and runoff after solving for surface energy balance and heat conduction in the glacial ice. The snow surface albedo was calculated based on snow density in the model (Yamazaki et al., 1993). We currently do not have detailed input data on the model calculations for Himalayan glaciers. Hence, in this study, the numerical experiments were carried out for a typical Tibetan glacier in Fig. 1 (Dongkemadi Glacier: $33.07^{\circ} \mathrm{N} ; 92.07^{\circ} \mathrm{E}$; $14.63 \mathrm{~km}^{2}$; 5275-5926 ma.s.1.) with the observed data by Fujita et al. (2007). As shown by Xu et al. (2006), the BCCs (elemental carbon in their case) over this glacier ranged from 18.2 to $168.2 \mu \mathrm{g} \mathrm{kg}^{-1}$ from snow pit works and the highest concentration was detected from a dirty layer. It indicates that Dongkemadi Glacier is also highly contaminated by seasonal BC depositions and can be considered to be suitable for our numerical experiments. The model calculated densitybased snow albedos were always reduced by applying the 

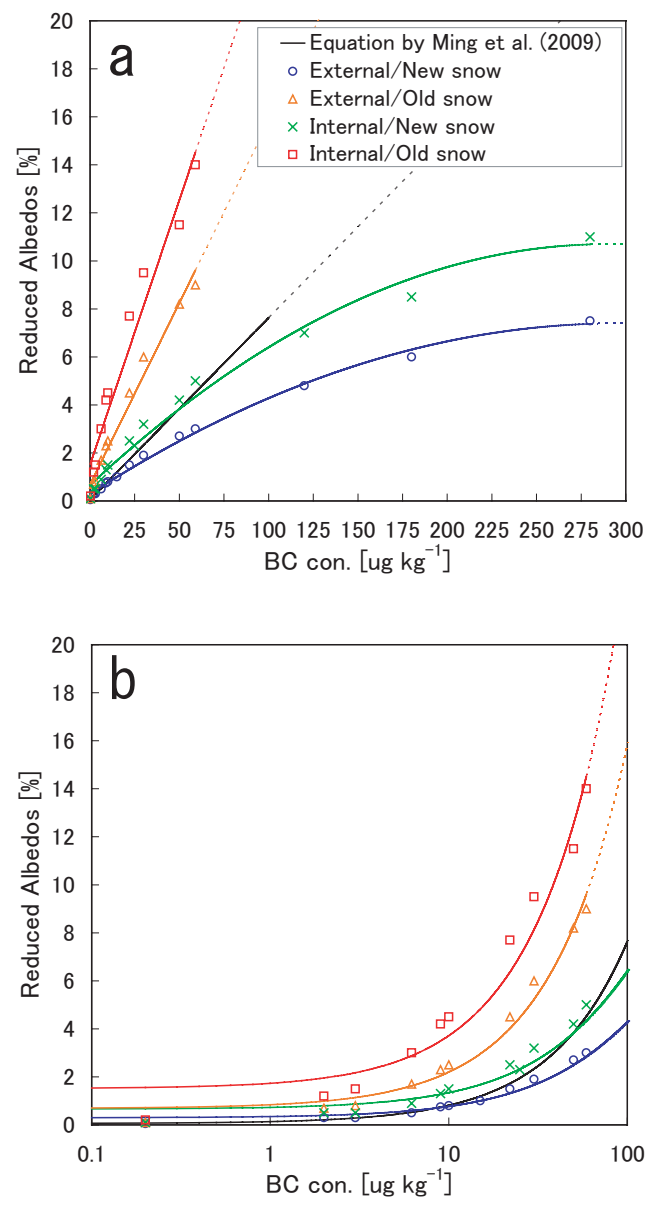

Fig. 7. Albedo reductions for 2 types of BC mixture conditions (external and internal mixture, called Ext and Int, respectively) with 2 types of snow conditions (new and old snow, called New and Old, respectively) together with the estimated albedo reductions by the equation of Ming et al. (2009). The employed data were based on the previous studies (Warren and Wiscombe, 1980, 1985; Grenfell et al., 1994; Hansen and Nazarenko, 2004; Jacobson, 2004). (b) denotes an enlarged (a) for the $\mathrm{BC}$ concentration range up to $100 \mu \mathrm{g} \mathrm{kg}^{-1}$ with $\log$ scale for $\mathrm{x}$-axis. The parts of dashed lines denote out of ranges of the employed data. If you use the data estimated from each equation in Table 3 , and refer to the dashed line for various studies, use caution in your discussion of albedo reductions because there are no supporting observations in these ranges.

albedo reductions of $2.0 \%$ or $5.2 \%$ related with $\mathrm{BCD}$ effect as evaluated in this study. We changed only the albedo settings; all the input data and other parameters were the same as those in Fujita (2007) and Fujita et al. (2007). In the experiments, forcing albedo reductions means that homogeneous mixture of $\mathrm{BC}$ at glacier surface always reduce snow surface albedo of 2.0-5.2\% compared to the control (density-based albedos). Runoff amount changes are due to surface albedo changes in the experiments. Total runoff amount means the sum of runoff for 1 year from 10 October, 1992.

The results show a corresponding increase in total annual runoff from 70 to $204 \mathrm{~mm}$ of water equivalent by melt wa- ter from the glacier especially due to the June-August melting (melting season) (Fig. 8). In this study, we considered the possibility that the dark snow layer, due to $\mathrm{BC}$ depositions during pre-monsoon season, simply continues after pre-monsoon season. Thus, if the albedo reductions of $2.0-5.2 \%$ continues after the pre-monsoon season, the total runoff increases due to albedo changes corresponds to 11.6-33.9\% of annual discharge of the Tibetan glacier. This estimate is based on the comparison of the annual runoff amount, roughly determined from the difference between annual precipitation of $672 \mathrm{~mm}$ (observed) and evaporation of $70 \mathrm{~mm}$ (calculated) (Fujita and Ageta, 2000), to the calculated total increases of runoff amount due to the albedo reductions. Moreover, the acceleration of ablation processes in pre-monsoon season can cause the complete melting of snow cover, resulting in an advance in ice exposure to the solar radiation, causing an additional reduction of surface albedo and more discharge.

Over Dongkemadi Glacier, air temperature begins to rise above freezing after June (Fujita et al., 2007), corresponding to the period of onset of monsoon. Hence, the effect of the albedo reduction on runoff increase, appears after June. In our numerical tests, we considered that the effects of albedo reductions in the transient period from pre-monsoon to monsoon corresponds to the snow darkening effect due to the integrated $\mathrm{BC}$ depositions on snow surface during premonsoon season (March-May). The albedo reductions before monsoon season should not actually affect runoff increase in the study by Fujita (2007) because precipitation fallen in the succeeding monsoon season covered the darkened surface. However, if global warming expands the period of melting season in future, the albedo reductions during pre-monsoon will be an important factor in increasing snow melt runoff from this glacier because of re-exposure of dirty surface by BC to the snow surface as indicated in Fujita (2007). In addition, rainfall below equilibrium line may sometimes contribute to re-exposures of $\mathrm{BC}$ layer to the surface with albedo reductions. The combination of upper and lower snow layer due to snow meltings, and the additional $\mathrm{BC}$ depositions by wet deposition, may also contribute to snow surface albedo reductions during monsoon season. However, quantitative discussions including all these effects are out of the scope of this study. In addition, BC flushing effect due to snow melting as discussed in Conway et al. (1996) and Flanner et al. (2007) may also be important for determining albedo reduction at the snow surface, but quantitative discussions are currently very difficult because of very limited studies. Future studies on this flushing effect on impurities may, perhaps, modify snow albedo estimation to some extent.

Although the numerical experiments were carried out at a different location a little way from NCO-P site, some hints about the sensitivities of these albedo reductions on snowmelt runoff can be provided by this work. 


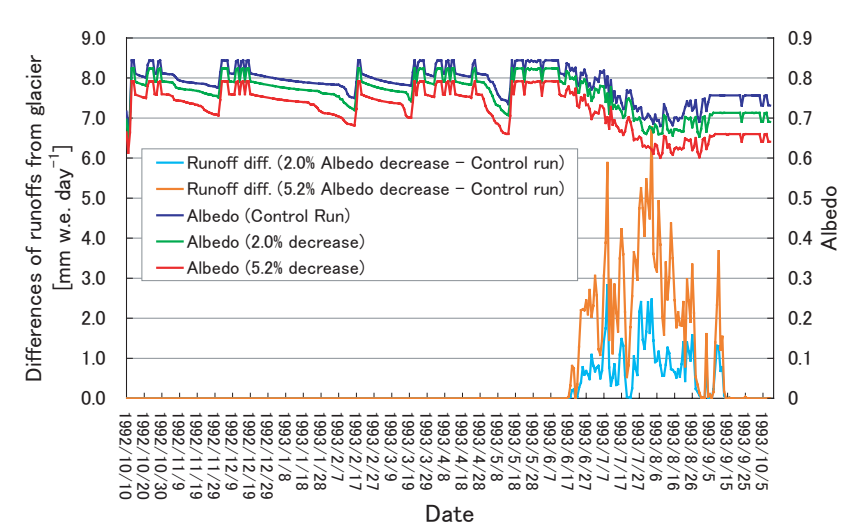

Fig. 8. Increases of snow melt runoff from Dongkemadi Glacier due to continuous albedo reductions of $2.0 \%$ and $5.2 \%$ in the numerical experiments. The lines in blue, green, and red denote the areal weighted mean of snow albedos along each altitude in the domain of Fujita (2007) and Fujita et al. (2007) for the cases of control run (no forced albedo reduction), $2.0 \%$ albedo reduction, and $5.2 \%$ albedo reduction, respectively. The lines in sky blue and orange denote the differences in snow melt runoff from the glacier between the cases of $2.0 \%$ albedo reduction and control run and between $5.2 \%$ albedo reduction and control run, respectively.

\subsection{Suggested future studies on snow albedo over the Himalayas}

Because our estimation on snow albedo reductions is lower bound, more increase of snow melt can probably occur over NDC snow surface due to other atmospheric processes, snow aging, and additional mineral dust deposition. For better elucidating these processes, further observations and model studies for BC and dust deposition onto Himalayan regions, and their effects on snow albedo feedback, are needed.

We would like to suggest the following additional areas of study to further illuminate the $\mathrm{BC}$ and dust impact on the NDC parts of Himalayan and Tibetan glaciers. We need more direct observations of $\mathrm{BC}$ and dust on deposition and concentration in the snow surface over Himalayan and Tibetan regions in order to develop an understanding of the precise impurity effects on albedo reductions. To know the mixture state of impurity in snow, it is important to carry out more detailed studies on 1) the dilution and enrichment effects of $\mathrm{BC}$ and dust by precipitation, 2) the snow surface melting, and the combination between the snow surface layer and the snow layer below the snow surface, including 3 ) the wet depositions of $\mathrm{BC}$ and dust and flushing by melt water and precipitation. Although BC and dust can reduce snow surface albedos, we should know the equilibrium albedo reduction, specifically, maximal albedo reduction, in the mixture of the impurities. Regional and global models in higher horizontal resolution with realistic high-mountain, snow-pack physics are also a very helpful means for understanding the albedo reductions, and related snow processes throughout the Himalayan and Tibetan regions.

\section{Conclusions}

We estimated a BCD amount of $266 \mu \mathrm{g} \mathrm{m}^{-2}$ $\left(=2.89 \mu \mathrm{g} \mathrm{m}^{-2} \mathrm{day}^{-1}\right)$ from dry deposition during premonsoon season over NDC parts of a Himalayan glacier at a similar altitude of NCO-P site. Assuming the BCD is distributed uniformly on a pure $2-\mathrm{cm}$ surface snow layer, we estimated BCC of $26.0-68.2 \mu \mathrm{g} \mathrm{kg}^{-1}$ within the range of the density at Yala glacier, which is in agreement with the observations from southwestern Chineses glaciers. Hence, our estimated $\mathrm{BCC}$ range is considered to be realistic as lower bound BCC level at the southern slopes of Himalayas. Assuming that the $\mathrm{BCC}$ range in snow is also representative near NCO-P and estimating albedo reductions by the BCC, the decreases of surface snow albedo of $2.0-5.2 \%$ were expected. If we assume these albedo reductions continues throughout the year, a possible 70-204 $\mathrm{mm}$ of water equivalent runoff increase from a typical Tibetan glacier was found from simple model experiments. It represents a significant amount of the annual drainage from the glacier. Our results are applicable to NDC parts of glaciers. However, the estimate is likely to represent a lower bound for snow albedo reductions, since atmospheric wind and turbulence effects, snow aging, dust deposition, and snow albedo feedbacks were not considered. When all these processes are included, the actual snow albedo reduction over NDC parts in Himalayan glaciers is likely to be higher with more consequences on surface water runoffs from snow-ice melting. For these reasons we need more observations of BCC and BCD in Himalayan regions, better estimation of albedo reductions, and better information of snow physical parameters in the regions. This information can be gathered by satellite and model studies in the near future and then used for assessing snow albedo feedbacks and accompanied snow melt runoff from glaciers.

Acknowledgements. All the observed particle data, eqBCC, and meteorological data in the atmosphere were obtained at NCO-P site in the framework of the Ev-K ${ }^{2}$-CNR "SHARE-Asia" and UNEP "ABC" projects. This research is conducted under the Joint Aerosol Monsoon Experiment (JAMEX). Mian Chin at NASA/GSFC and Qian Tan at GEST/UMBC (NASA/GSFC) provided useful comments on BCD. This work is partially supported by the NASA Interdisciplinary Investigation Program, which supported a visiting fellowship at the University of Maryland at Baltimore County for the first author. I appreciate Jan Angevine, at NASA/GSFC, for proofreading our paper.

Edited by: J. J. Schauer 


\section{References}

Aoki, Te., Aoki, Ta., Fukabori, M., Hachikubo, A., Tachibana, Y., and Nishio, F.: Effects of snow physical parameters on spectral albedo and bidirectional reflectance of snow surface, J. Geophys. Res., 105(D8), 10219-10236, 2000.

Aoki, Te., Motoyoshi, H., Kodama, Y., Yasunari, T. J., Sugiura, K., and Kobayashi, H.: Atmospheric aerosol deposition on snow surfaces and its effect on albedo, SOLA, 2, 1316, doi:10.2151/sola.2006-004, available online at: http://www. jstage.jst.go.jp/article/sola/2/0/2_13/_article, 2006.

Aoki, Te., Motoyoshi, H., Kodama, Y., Yasunari, T. J., and Sugiura, K.: Variations of the snow physical parameters and their effects on albedo in Sapporo, Japan, Ann. Glaciol., 46, 375-381, 2007.

Bollasina, M., Bertolani, L., and Tartari, G.: Meteorological observations at high altitude in the Khumbu Valley, Nepal Himalayas, 1994-1999, Bull. Glaciol. Res., 19, 1-11, available online at: http://www.seppyo.org/ bgr/19/BGR19P1.PDF, 2002.

Bonasoni, P., Laj, P., Angelini, F., Arduini, J., Bonafè, U., Calzolari, F., Cristofanelli, P., Decesari, S., Facchini, M. C., Fuzzi, S., Gobbi, G. P., Maione, M., Marinoni, A., Petzold, A., Roccato, F., Roger, J. C., Sellegri, K., Sprenger, M., Venzac, H., Verza, G. P., Villani, P., and Vuillermoz, E.: The ABC-Pyramid Atmospheric Research Observatory in Himalaya for aerosol, ozone and halocarbon measurements, Sci. Total Environ., 391(2-3), 252-261, 2008.

Bonasoni, P., Laj, P., Marinoni, A., Sprenger, M., Angelini, F., Arduini, J., Bonafè, U., Calzolari, F., Colombo, T., Decesari, S., Di Biagio, C., di Sarra, A. G., Evangelisti, F., Duchi, R., Facchini, M. C., Fuzzi, S., Gobbi, G. P., Maione, M., Panday, A., Roccato, F., Sellegri, K., Venzac, H., Verza, G. P., Villani, P., Vuillermoz, E., and Cristofanelli, P.: Atmospheric Brown Clouds in the Himalayas: first two years of continuous observations at the Nepal-Climate Observatory at Pyramid (5079 m), Atmos. Chem. Phys. Discuss., 10, 4823-4885, doi:10.5194/acpd10-4823-2010, 2010.

Cong, Z., Kang, S., and Qin, D.: Seasonal features of aerosol particles recorded in snow from Mt. Qomolangma (Everest) and their environmental implications, J. Environ. Sci., 21(7), 914919, 2009.

Cong, Z., Kang, S., Dong, S., Liu, X., and Qin, D.: Elemental and individual particle analysis of atmospheric aerosols from high Himalayas, Environ. Monit. Assess., 160, 323-335, doi:10.1007/s10661-008-0698-3, 2010.

Conway, H., Gades, A., and Raymond C. F.: Albedo of dirty snow during conditions of melt, Water Resour. Res., 32(6), 1713-1718, 1996.

Decesari, S., Facchini, M. C., Carbone, C., Giulianelli, L., Rinaldi, M., Finessi, E., Fuzzi, S., Marinoni, A., Cristofanelli, P., Duchi, R., Bonasoni, P., Vuillermoz, E., Cozic, J., Jaffrezo, J. L., and Laj, P.: Chemical composition of $\mathrm{PM}_{10}$ and $\mathrm{PM}_{1}$ at the highaltitude Himalayan station Nepal Climate Observatory-Pyramid (NCO-P) (5079 m a.s.1.), Atmos. Chem. Phys., 10, 4583-4596, doi:10.5194/acp-10-4583-2010, 2010.

Flanner, M. G., Zender, C. S., Randerson, J. T., and Rasch, P. J.: Present-day climate forcing and response from black carbon in snow, J. Geophys. Res., 112(D11), D11202, doi:10.1029/2006JD008003, 2007.

Flanner, M. G., Zender, C. S., Hess, P. G., Mahowald, N. M., Painter, T. H., Ramanathan, V., and Rasch, P. J.: Springtime warming and reduced snow cover from carbonaceous particles, Atmos. Chem. Phys., 9, 2481-2497, doi:10.5194/acp-9-24812009, 2009.

Fujita, K., Takeuchi, N., and Seko, K.: Glaciological observations of Yala Glacier in Langtang Valley, Nepal Himalayas, 1994 and 1996, Bull. Glaciol. Res., 16, 75-81, available online at: http: //www.seppyo.org/ bgr/16/BGR16P75.PDF, 1998.

Fujita, K. and Ageta, Y.: Effect of summer accumulation on glacier mass balance on the Tibetan Plateau revealed by mass-balance model, J. Glaciol., 46, 244-252, 2000.

Fujita, K.: Effect of dust event timing on glacier runoff: sensitivity analysis for a Tibetan glacier, Hydrol. Process., 21(21), 28922896, doi:10.1002/hyp.6504, 2007.

Fujita, K., Ohta, T., and Ageta, Y.: Characteristics and climatic sensitivities of runoff from a cold-type glacier on the Tibetan Plateau, Hydrol. Process., 21(21), 2882-2891, doi:10.1002/hyp.6505, 2007.

Grenfell, T. C., Warren, S. G., and Mullen, P. C.: Reflection of Solar-Radiation by the Antarctic Snow Surface at Ultraviolet, Visible, and near-Infrared Wavelengths, J. Geophys. Res., 99(D9), 18669-18684, 1994.

Hadley, O. L., Ramanathan, V., Carmichael, G. R., Tang, Y., Corrigan, C. E., Roberts, G. C., and Mauger, G. S.: TransPacific transport of black carbon and fine aerosols $(\mathrm{D}<2.5 \mathrm{mu}$ m) into North America, J. Geophys. Res., 112(D5), D05309, doi:05310.01029/02006JD007632, 2007.

Han, Z. W., Ueda, H., Matsuda, K., Zhang, R. J., Arao, K., Kanai, Y., and Hasome, H.: Model study on particle size segregation and deposition during Asian dust events in March 2002, J. Geophys. Res., 109(D19), D19205, doi:19210.11029/12004JD004920, 2004.

Hansen, J. and Nazarenko, L.: Soot climate forcing via snow and ice albedos, P. Natl. Acad. Sci. USA, 101(2), 423-428, 2004.

Holland, D. M.: Merged IBCAO/ETOPO5 Global Topographic Data Product. National Geophysical Data Center (NGDC), Boulder Colorado, available online at: http://fish.cims.nyu.edu/ project_aomip/forcing_data/topography/merged/overview.html, 2000.

IPCC: Summary for Policymakers, in: Climate Change 2007: The Physical Science Basis. Contribution of Working Group I to the Fourth Assessment Report of the Intergovernmental Panel on Climate Change, edited by: Solomon, S., Qin, D., Manning, M., Chen, Z., Marquis, M., Averyt, K. B., Tignor, M., and Miller, H. L.: Cambridge University Press, Cambridge, United Kingdom and New York, NY, USA, 2007.

Jacobson, M. Z.: Climate response of fossil fuel and biofuel soot, accounting for soot's feedback to snow and sea ice albedo and emissivity, J. Geophys. Res., 109, D21201, doi:10.1029/2004JD004945, 2004.

Karma, Ageta, Y., Naito, N., Iwata, S., and Yabuki, H.: Glacier distribution in the Himalayas and glacier shrinkage from 1963 to 1993 in the Bhutan Himalayas, Bull. Glaciol. Res., 20, 29-40, available online at: http://www.seppyo.org/ bgr/20/BGR20P29. pdf, 2003.

Lau, K. M., Kim, M. K., and Kim, K. M.: Asian summer monsoon anomalies induced by aerosol direct forcing: the role of the Tibetan Plateau, Clim. Dynam., 26(7-8), 855-864, 2006.

Lau, K. M., Ramanathan, V., Wu, G.-X., Li, Z., Tsay, S. C., Hsu, C., Sikka, R., Holben, B., Lu., D., Tartari, G., Chin, M., Koudelova, 
P., Chen, H., Ma, Y., Huang, J., Taniguchi, K., and Zhang, R.: The Joint Aerosol-Monsoon Experiment - A new challenge for monsoon climate research, B. Am. Meteorol. Soc., 89(3), 369383, doi:10.1175/BAMS-89-3-369, 2008.

Lau, K. M., Kim, M. K., and Kim, K. M.: Enhanced surface warming and snow melt in the Himalayas and Tibetan Plateau induced by the EHP effect, Environ. Res. Lett., 5, 025204, doi:10.1088/1748-9326/5/2/025204, 2010.

Lindstedt, P. R.: Simplified soot nucleation and surface growth steps for non-premixed flame, in: Soot Formation in Combustion: Mechanisms and Models, edited by: Bockhorn, H., SpringerVerlag, Berlin, 417-441, 1994.

Marcq, S., Laj, P., Roger, J. C., Villani, P., Sellegri, K., Bonasoni, P., Marinoni, A., Cristofanelli, P., Verza, G. P., and Bergin, M.: Aerosol optical properties and radiative forcing in the high Himalaya based on measurements at the Nepal Climate Observatory-Pyramid site (5079 m a.s.1.), Atmos. Chem. Phys., 10, 5859-5872, doi:10.5194/acp-10-5859-2010, 2010.

Marinoni, A., Cristofanelli, P., Laj, P., Duchi, R., Calzolari, F., Decesari, S., Sellegri, K., Vuillermoz, E., Verza, G. P., Villani, P., and Bonasoni, P.: Aerosol mass and black carbon concentrations, two year-round observations at NCO-P (5079 m, Southern Himalayas), Atmos. Chem. Phys. Discuss., 10, 8379-8413, doi:10.5194/acpd-10-8379-2010, 2010.

Ming, J., Cachier, H., Xiao, C., Qin, D., Kang, S., Hou, S., and $\mathrm{Xu}, \mathrm{J}$.: Black carbon record based on a shallow Himalayan ice core and its climatic implications, Atmos. Chem. Phys., 8, 13431352, doi:10.5194/acp-8-1343-2008, 2008.

Ming, J., Xiao, C., Cachier, H., Qin, D., Qin, X., Li, Z., and Pu, J.: Black Carbon (BC) in the snow of glaciers in west China and its potential effects on albedos, Atmos. Res., 92(1), 114-123, 2009.

Nho-Kim, E.-Y., Michou, M., and Peuch, V.-H.: Parameterization of size-dependent particle dry deposition velocities for global modeling, Atmos. Environ., 38, 1933-1942, 2004.

Petzold, A., Kramer, H., and Schönlinner, M.: Continuous measurement of atmospheric black carbon using a Multi-Angle Absorption Photometer, Environ. Sci. \& Pollut. Res., Special Issue 4, 78-82, 2002.

Ramanathan, V., Li, F., Ramana, M. V., Praveen, P. S., Kim, D., Corrigan, C. E., Nguyen, H., Stone, E. A., Schauer, J. J., Carmichael, G. R., Adhikary, B., and Yoon, S. C.: Atmospheric brown clouds: Hemispherical and regional variations in longrange transport, absorption, and radiative forcing, J. Geophys. Res., 112, D22S21, doi:10.1029/2006JD008124, 2007.
Tanikawa, T., Stamnes, K., Aoki, T., Kuchiki, K., Hachikubo, A., and Sugiura, K.: Effect of snow impurities and vertical profile on snow albedo and reflectance, Eos Trans. AGU, 90(52), Fall Meet. Suppl., Abstract C33C-0519, 2009.

Uno, I., Eguchi, K., Yumimoto, K., Takemura, T., Shimizu, A., Uematsu, M., Liu, Z., Wang, Z., Hara, Y., and Sugimoto, N.: Asian dust transported one full circuit around the globe, Nature Geosci., 2, 557-560, doi:10.1038/NGEO583, 2009.

Venzac, H., Sellegri, K., Laj, P., Villani, P., Bonasoni, P., Marinoni, A., Cristofanelli, P., Calzolari, F., Fuzzi, S., Decesari, S., Facchini, M.-C., Vuillermoz, E., and Verza, G. P.: High frequency new particle formation in the Himalayas, P. Natl. Acad. Sci. USA, 105(41), 15666-15671, 2008.

Warren, S. G. and Wiscombe, W. J.: A Model for the Spectral Albedo of Snow .2. Snow Containing Atmospheric Aerosols, J. Atmos. Sci., 37(12), 2734-2745, 1980.

Warren, S. G. and Wiscombe, W. J.: Dirty snow after nuclear war, Nature, 313, 467-470, 1985.

Xu, B., Yao, T., Liu, X., and Wang, N.: Elemental and organic carbon measurements with a two-step heating-gas chromatography system in snow samples from the Tibetan Plateau, Ann. Glaciol., 43, 257-262, 2006.

Xu, B., Wang, M., Joswiak, D. R., Cao, J., Yao, T., Wu, G., Yang, W., and Zhao, H.: Deposition of anthropogenic aerosols in a southeastern Tibetan glacier, J. Geophys. Res., 114, D17209, doi:10.1029/2008JD011510, 2009a.

Xu, B., Cao, J., Hansen, J., Yao, T., Joswiak, D. R., Wang, N., Wu, G., Wang, M., Zhao, H., Yang, W., Liu, X., and He, J.: Black soot and the survival of Tibetan glaciers, P. Natl. Acad. Sci. USA, 106(52), 22114-22118, doi:10.1073/pnas.0910444106, $2009 \mathrm{~b}$.

Yamazaki, T., Kondo, J., Sakuraoka, T., and Nakamura, T.: A onedimensional model of the evolution of snow-cover characteristics, Ann. Glaciol., 18, 22-26, 1993.

Yasunari, T. J. and Yamazaki, K.: Impacts of Asian dust storm associated with the stratosphere-to-troposphere transport in the spring of 2001 and 2002 on dust and tritium variations in Mount Wrangell ice core, Alaska, Atmos. Environ., 43, 2582-2590, doi: 10.1016/j.atmosenv.2009.02.025, 2009. 